Pacific Journal of Mathematics

MULTISECTIONED PARTITIONS OF INTEGERS 


\title{
MULTISECTIONED PARTITIONS OF INTEGERS
}

\author{
RICHARD M. GRASSL
}

This paper presents identities on generating functions for multisectioned partitions of integers by developing in the language of partitions some powerful and essentially combinatorial techniques from the literature of principal differential ideals. D. Mead has stated in Vol. 42 of this journal that one can obtain interesting combinatorial relations by constructing different vector space bases for a subspace of a differential ring and using the fact that the cardinality of all bases is the same. The results of the present paper are of this nature.

In particular, we enumerate certain sets of ordered pairs of generalized tableaux that have a central role in Mead's paper. Tableaux were used by A. Young and others to study the structure of the symmetric groups $S_{n}$. In [3], D. Knuth used an "insertion into tableau" construction of $\mathrm{C}$. Schensted to give a direct 1-to-1 correspondence between "generalized permutations" and ordered pairs of "generalized Young tableaux" having the same shape. In [5], Mead independently proved the existence of such a bijection while developing a new vector space basis for the ring of differential polynomials in $n$ independent differential indeterminates. Mead's paper deals with principal differential ideals generated by Wronskians and used determinantal identities going back to Cayley. The ordered pairs of generalized tableaux used by Mead appear in a more general setting in the paper [1] by Doubilet, Rota, and Stein.

1. Multisectioned partitions, Let $w$ be a nonnegative integer. Here a partition of $w$ into $d$ parts, or of degree $d$, is a $d$-tuple $\left(p_{1}, \cdots p_{d}\right)$ of nonnegative integers $p_{k}$ with $p_{1} \leqq p_{2} \leqq \cdots \leqq p_{d}$ and $w=p_{1}+\cdots+p_{d}$. If $d=0$, we agree that there is one (ideal) partition of 0 but no partition of any $w>0$.

Let $P=\left(P_{1}, \cdots, P_{n}\right)$, where $P_{i}$ is a partition of $w_{i}$ of degree $d_{i}$, and let $w=w_{1}+\cdots+w_{n}$; then $P$ is an $n$-section partition of $w$ with signature $D=\left[d_{1}, \cdots, d_{n}\right]=\operatorname{sig} P$ and the weight of $P$ is $w$.

For applications to differential algebra, it is convenient to use two rowed matrices

$$
M=\left(\begin{array}{llll}
i_{1} & i_{2} & \cdots & i_{d} \\
j_{1} & j_{2} & \cdots & j_{d}
\end{array}\right)
$$

in which $i_{k} \in\{1,2, \cdots, n\}, j_{k} \in\{0,1, \cdots\}, i_{k} \leqq i_{k+1}$ for $1 \leqq k<d$, and 
$j_{k} \leqq j_{k+1}$ whenever $i_{k}=i_{k+1}$. (These are sometimes called generalized permutations (e.g., see D. E. Knuth [3], p. 710.) The $M$ of (1) can be associated in a 1-to-1 manner with the $n$-section partition

$$
P=P(M)=\left(P_{1}, \cdots, P_{n}\right)
$$

in which, for $1 \leqq h \leqq n, P_{h}$ has as its parts the $j_{k}$ with $i_{k}=h$.

Let $y_{i j}(i=1,2, \cdots, n ; j=0,1, \cdots)$ form a denumerable set of algebraically independent indeterminates over a field $F$ and let $R=$ $F\left[y_{i j}\right]$ denote the ring of polynomials in the $y_{i j}$ with coefficients in $F$. (Each of the sequences $\left\{y_{i 0}, y_{i 1}, y_{i 2}, \cdots\right\}$ is said to be a differential indeterminate $y_{i}$ ) Corresponding to an $M$ as in (1), or a $P$ as in (2), is the power product

$$
\pi=y_{i_{1} j_{1}} y_{i_{2} j_{2}} \cdots y_{i_{d} j_{d}} .
$$

The signature and weight of $\pi$ are defined to be the same as for the associated $n$-section partition $P$. The power products $\pi$ form a basis for $R$ as a vector space over $F$.

Let $T=\left(T_{1}, \cdots, T_{n}\right)$ be an $n$-section partition of $w$ with sig $T=$ $D=\left[d_{1}, \cdots d_{n}\right]$ and let $T_{i}=\left(t_{i 1}, \cdots, t_{i d_{i}}\right)$. If $T$ has the properties:

(a) $d_{1} \geqq d_{2} \geqq \cdots \geqq d_{n} \geqq 0$ and

(b) $t_{i j}<t_{i+1, j}$ for $1 \leqq i<n$ and $1 \leqq j \leqq d_{j+1}$ then $T$ is a (generalized Young) $n$-tableau with signature $D$ and weight $w$. Motivated by matrix notation, one considers $T_{i}$ to be the $i$ th row of $T$ and the transpose of $\left(t_{1 j}, t_{2 j}, \cdots, t_{r j}\right)$, where $r$ is the largest $i$ with $d_{i} \geqq j$, to be the $j$ th column of $T$.

The content of a sequence $a_{1}, a_{2}, \cdots, a_{d}$ of $d$ nonnegative integers $a_{i}$ whose largest term is $m$ is the $(m+1)$-tuple

$$
\left(c_{0}, c_{1}, \cdots, c_{m}\right)
$$

in which $c_{h}$ is the number of values of $i$ in $\{1,2, \cdots, d\}$ such that $a_{i}=h$. The content, con (P), of a $P$ as in (2), or of the associated $M$ of (1) or $\pi$ of (3), is the content of the sequence $j_{1}, \cdots, j_{d}$ on the second row of the $M$ of (1). The content of an $n$-tableau is its content as an $n$-section partition.

2. Generating functions for partitions. Let $N(w, d)$ be the number of partitions of $w$ with degree $d$. Then $N(0,0)=1$ and $N(w, 0)=0$ for $w>0$. Using the Cayley notation, let

$$
(d)=(1-x)\left(1-x^{2}\right) \cdots\left(1-x^{d}\right), \quad(0)=1,
$$

and let $\left[\begin{array}{c}h+k \\ h\end{array}\right]$ denote the generalized binomial coefficient $(\boldsymbol{h}+\boldsymbol{k}) /(\boldsymbol{h})(\boldsymbol{k})$. The generating function for $N(w, d)$ is well-known to be 


$$
\sum_{w=0}^{\infty} N(w, d) x^{w}=\frac{1}{(d)}=\frac{1}{(1-x)\left(1-x^{2}\right) \cdots\left(1-x^{d}\right)} .
$$

Then the generating function for the number of $n$-section partitions of $w$ with signature $\left[d_{1}, \cdots, d_{n}\right]$ is easily seen to be $1 /\left(d_{1}\right)\left(d_{2}\right) \cdots\left(d_{n}\right)$.

3. Limited 2-section partitions. The lemmas of this and the following section are needed below.

LEMMA 1. Let $d, q$, and $w$ be nonnegative integers.

(i) For $i=0, \cdots, d$, let $S_{i}$ be the set of all 2-section partitions $(Z, A)$ of $w-i(q+1)$ with signature $[j, i], i+j=d$, and with each part $z_{k}$ of $Z$ satisfying $z_{k} \leqq q$. Then there is a bijection $\sigma$ from the set $T$ of partitions $P$ of $w$ with degree $d$ onto the union $S=$ $S_{0} \cup S_{1} \cup \cdots \cup S_{d}$.

$$
\frac{1}{(\boldsymbol{d})}=\sum_{i=0}^{d} \frac{(\boldsymbol{q}+\boldsymbol{d}-\boldsymbol{i}) x^{i(q+1)}}{(\boldsymbol{q})(\boldsymbol{d}-\boldsymbol{i})(\boldsymbol{i})}=\sum_{i+j=d}\left[\begin{array}{c}
q+j \\
q
\end{array}\right] \frac{x^{i(q+1)}}{(\boldsymbol{i})} .
$$

Proof. (i) Let $P=\left(p_{1}, \cdots, p_{d}\right)$ be a member of $T$. Let $j$ be the largest subscript such that $p_{j} \leqq q$ and $i=d-j$. Subtracting $q+1$ from each of the $i$ parts $p_{j+1}, \cdots, p_{d}$ yields the 2-section partition $\sigma(P)=(Z, A)$ with $Z=\left(p_{1}, \cdots, p_{j}\right)$, and $A=\left(p_{j+1}-q-1\right.$, $\left.\cdots, p_{d}-q-1\right)$. It is readily seen that $\sigma$ is the desired bijection.

(ii) The generating function for the number of partitions of $w$ having degree $j=d-i$ with maximum part $q$ is $\left[\begin{array}{c}q+j \\ q\end{array}\right]=(q+j)(q)(j)$ (see Riordan, An Introduction to Combinatorial Analysis, especially p. 153, Problem 5). The generating function for partitions of $w$ with degree $i$ having parts greater than $q$ is $x^{i(q+1)} /(i)$. Forming the Cauchy product of these two generating functions and summing over $i=0,1, \cdots, d$ yields the identity in (ii).

4. Levi 3-section partitions, A Levi 3-section partition of $w$ having signature $[f, g, h]$ is a 3 -section partition $(U, V, W)$ with $U=$ $\left(u_{1}, u_{2}, \cdots, u_{f}\right), \quad V=\left(v_{1}, v_{2}, \cdots, v_{g}\right)$, and $W=\left(w_{1}, w_{2}, \cdots, w_{h}\right)$ with the property that $v_{1} \geqq f$. The following lemma makes more accessible an essentially combinatorial result contained in the proof of an important theorem in differential algebra by $\mathrm{H}$. Levi [4].

LEMMA 2. (i) There is a bijection $\theta$ from the set of all 2-section partitions of $w$ having signature $[d, e]$ onto the set of all Levi 3-section partitions of $w$ having signature of the form $[d-h, e-h, h]$ with $0 \leqq h \leqq \mu=\min \{d, e\}$. 
(ii)

$$
\frac{1}{(\boldsymbol{d})(\boldsymbol{e})}=\sum_{h=0}^{\mu} \frac{x^{(d-h)(e-h)}}{(\boldsymbol{d}-\boldsymbol{h})(\boldsymbol{e}-\boldsymbol{h})(\boldsymbol{h})}=\sum_{\substack{h+a=d \\ h+b=e}} \frac{x^{a b}}{(\boldsymbol{a})(\boldsymbol{b})(\boldsymbol{h})} .
$$

Proof. (i) Let $(B, C)$ be a 2-section partition of $w$ with signature $[d, e]$ where $B=\left(b_{1}, \cdots, b_{d}\right), C=\left(c_{1}, \cdots, c_{e}\right)$. The bijection $\theta(B, C)=$ $(U, V, W)$ is constructed as follows. If $c_{1} \geqq d$, we let $h=0, U=$ $B, V=C$ and $W$ be the (ideal) partition of 0 with degree 0 . If $c_{1}<d$, let $h$ be the largest positive integer $m$ with $m+c_{m} \leqq d$. For $k=$ $1, \cdots, h$ let

$$
i(k)=k+c_{k}, w_{k}=b_{i(k)}+c_{k} .
$$

Since the $b$ 's and $c$ 's are nondecreasing, so are the $w$ 's, i.e., $W=$ $\left(w_{1}, \cdots, w_{h}\right)$ is a partition. Let $v_{j}=c_{j+h}$ and $V=\left(v_{1}, \cdots, v_{e-h}\right)$. For $1 \leqq k \leqq h$, we delete the $b_{i(k)}$ from $B$ and let $U=\left(u_{1}, \cdots, u_{d-h}\right)$, where the $u$ 's are the remaining $b$ 's in their same relative order. Now we let $\theta(B, C)=(U, V, W)$. It is easily seen that the first part $v_{1}$ of $V$ is at least as large as the degree $d-h$ of $U$.

It remains to show that $\theta$ is a bijection. Let $(U, V, W)$ be a Levi 3 -section partition. We show below that $U, V$, and a part $w_{k}$ of $W$ uniquely determine the nonnegative integers $b_{i(k)}$ and $c_{k}$ to be reinserted into $U$ and $V$, respectively, in the process of rebuilding them into partitions $B$ and $C$ such that $\theta(B, C)=(U, V, W)$.

For this purpose only, we introduce the ideal values $u_{0}=-1$ and $u_{f+1}=\infty$. Then each nonnegative integer $w$ satisfies

$$
u_{r} \leqq w-\gamma \leqq u_{\gamma+1}
$$

for some $\gamma$ in $\{0,1, \cdots, \min (f, w)\}$. This $\gamma=\gamma(w)$ is unique since

$$
u_{\gamma} \leqq w-\gamma \leqq u_{\gamma+1} \leqq \cdots \leqq u_{\gamma+\delta} \leqq w-(\gamma+\delta) \leqq u_{\gamma+\delta+1},
$$

with $\delta \geqq 1$, gives the contradiction $w-\gamma \leqq w-\gamma-\delta$. Now one sees from (4) that $c_{k}$ must be $\gamma\left(w_{k}\right)$ and $b_{i(k)}$ must be $w_{k}-c_{k}$. Hence $\theta$ is a bijection.

Part (ii) merely restates part (i) in terms of generating functions.

5. Special $3 n$-section partitions. Let $q_{1}, q_{2}, \cdots, q_{n}, q_{n+1}$ be fixed nonnegative integers. Denote this sequence by $Q$. Let

$$
\begin{aligned}
& Z_{i}=\left(z_{i 1}, \cdots, z_{i r_{i}}\right) \text { with } z_{i j} \leqq q_{i} \text { for } 1 \leqq i \leqq n+1, \\
& U_{i}=\left(u_{i 1}, \cdots, u_{i s_{i}}\right) \text { for } 1 \leqq i \leqq n, \text { and } \\
& V_{i}=\left(v_{i 1}, \cdots, v_{i t_{i}}\right) \text { for } 1 \leqq i \leqq n-1
\end{aligned}
$$

be partitions of degree $r_{i}, s_{i}$, and $t_{i}$ respectively. The $3 n$-section partition 


$$
L=\left(Z_{1}, Z_{2}, \cdots, Z_{n+1}, U_{1}, \cdots, U_{n}, V_{1}, \cdots V_{n-1}\right)
$$

of $w$ is said to be special (with respect to $Q$ ) if $s_{i} \leqq v_{i 1}$ for $1 \leqq i \leqq$ $n-1$.

THEOREM 1. (i) There is a 1-to-1 correspondence between the set $E(w, D)$ of all $n$-section partitions of $w$ with signature $D=$ $\left[d_{1}, d_{2}, \cdots, d_{n}\right]$ and the set $F(w, D)$ of all special $3 n$-section partitions $L$, as in (5), of $w$ with signature $\left[r_{1}, \cdots, r_{n+1}, s_{1}, \cdots, s_{n}, t_{1}, \cdots, t_{n-1}\right]$ satisfying the following system of conditions:

$$
\left\{\begin{array}{c}
d_{1}=s_{1}+s_{2}+\cdots+s_{n}+r_{1}+r_{n+1} \\
d_{2}=t_{1}+s_{2}+\cdots+s_{n}+r_{2}+r_{n+1} \\
d_{3}=t_{2}+s_{3}+\cdots+s_{n}+r_{3}+r_{n+1} \\
\vdots \\
\vdots \\
d_{n}=t_{n-1}+s_{n}+r_{n}+r_{n+1}
\end{array}\right.
$$

(ii) Let

$$
\varepsilon=\left[\sum_{i=1}^{n}\left(d_{i}-r_{i}\right)\left(q_{i}+1\right)+\sum_{i=1}^{n-1} s_{i} t_{i}\right]+s_{n}\left(q_{n+1}+1\right) .
$$

Then

$$
\begin{aligned}
\frac{1}{\left(\boldsymbol{d}_{1}\right)\left(\boldsymbol{d}_{2}\right) \cdots\left(\boldsymbol{d}_{n}\right)}= & \sum \frac{x^{\varepsilon}}{\varepsilon\left(\boldsymbol{t}_{1}\right) \cdots\left(\boldsymbol{t}_{n-1}\right)\left(\mathbf{s}_{1}\right) \cdots\left(\boldsymbol{s}_{n}\right)} \\
& \cdot\left[\begin{array}{c}
q_{1}+r_{1} \\
q_{1}
\end{array}\right] \cdots\left[\begin{array}{c}
q_{n+1}+r_{n+1} \\
q_{n+1}
\end{array}\right]
\end{aligned}
$$

where the sum is taken over all $r_{i}, s_{i}$, and $t_{i}$ satisfying system of equations in (6).

Proof. (i) Let $P=\left(P_{1}, \cdots, P_{n}\right)$ be an $n$-section partition of $w$ with signature $\left[d_{1}, \cdots, d_{n}\right]$. For $1 \leqq i \leqq n$, let $P_{i}=\left(p_{i 1}, \cdots, p_{i d_{i}}\right)$. The $\sigma$ bijection of Lemma 1(i), using $q_{i}$ for $q$ and $d_{i}$ for $d$, applied to the $P_{i}$ yields

$$
\sigma\left(P_{i}\right)=\left(Z_{i}, A_{i}\right), \quad i=1,2, \cdots, n
$$

where the 2-section partition $\left(Z_{i}, A_{i}\right)$ has signature $\left[s_{i}, d_{i}-r_{i}\right]$. Let $\left(U_{1}, V_{1}, W_{1}\right)$ be the result of applying the $\theta$ bijection of Lemma 2(i) to $\left(A_{1}, A_{2}\right)$, i.e., let

$$
\theta\left(A_{1}, A_{2}\right)=\left(U_{1}, V_{1}, W_{1}\right) \text {. }
$$

Using the $W_{1}$ thus obtained, let

$$
\theta\left(W_{1}, A_{3}\right)=\left(U_{2}, V_{2}, W_{2}\right)
$$


Further applications of $\theta$ yield

$$
\begin{gathered}
\theta\left(W_{2}, A_{4}\right)=\left(U_{3}, V_{3}, W_{3}\right) \\
\vdots \\
\theta\left(W_{n-2}, A_{n}\right)=\left(U_{n-1}, V_{n-1}, W_{n-1}\right) .
\end{gathered}
$$

Finally, using $q_{n+1}$ for $q$, apply $\sigma$ to $W_{n-1}$ yielding

$$
\sigma\left(W_{n-1}\right)=\left(Z_{n+1}, U_{n}\right) \text {. }
$$

These constructions produce the $Z_{i}, U_{i}$, and $V_{i}$ of the desired special $3 n$-section partition $L$. The proof of part (ii) shows the development of the system (6). The map $P \rightarrow L$ is a bijection since $\sigma$ and $\theta$ are bijections.

(ii) Let $n=2$. Replacing $d, q$, and $j$ by $d_{1}, q_{1}$, and $r_{1}$ resp., and then by $d_{2}, q_{2}$, and $r_{2}$ resp., in Lemma 1(ii) we have

$$
\frac{1}{\left(\boldsymbol{d}_{1}\right)}=\sum_{i+r_{1}=d_{1}}\left[\begin{array}{c}
q_{1}+r_{1} \\
q_{1}
\end{array}\right] \frac{x^{i\left(q_{1}+1\right)}}{(\boldsymbol{i})}, \frac{1}{\left(\boldsymbol{d}_{2}\right)}=\sum_{k+r_{2}=d_{2}}\left[\begin{array}{c}
q_{2}+r_{2} \\
q_{2}
\end{array}\right] \frac{x^{k\left(q_{2}+1\right)}}{(\boldsymbol{k})}
$$

and the product

$$
\frac{1}{\left(\boldsymbol{d}_{1}\right)\left(\boldsymbol{d}_{2}\right)}=\sum_{i+r_{1}=d_{1}} \sum_{k+r_{2}=d_{2}} \frac{x^{i\left(q_{1}+1\right)+k\left(q_{2}+1\right)}}{(\boldsymbol{i})(\boldsymbol{k})}\left[\begin{array}{c}
q_{1}+r_{1} \\
q_{1}
\end{array}\right]\left[\begin{array}{c}
q_{2}+r_{2} \\
q_{2}
\end{array}\right] \text {. }
$$

Replacing $d, e, h, a$, and $b$ by $i, k, s, s_{1}$ and $t_{1}$ resp. in Lemma 2(ii) yields,

$$
\frac{1}{(i)(k)}=\sum_{\substack{s=s_{1}=2 \\ s+t_{1}=k}} \frac{x^{s_{1} t_{1}}}{\left(s_{1}\right)\left(t_{1}\right)(s)}
$$

Substituting (9) into (8) yields

$$
\frac{1}{\left(\boldsymbol{d}_{1}\right)\left(\boldsymbol{d}_{2}\right)}=\sum_{\substack{d_{1}=s_{1}+r_{1}+s \\
d_{2}=t_{1}+r_{2}+s}} \frac{x^{s_{1} t_{1}+\left(d_{1}-r_{1}\right)\left(q_{1}+1\right)+\left(d_{2}-r_{2}\right)\left(q_{2}+1\right)}}{\left(\boldsymbol{s}_{1}\right)\left(\boldsymbol{t}_{1}\right)(\boldsymbol{s})}\left[\begin{array}{c}
q_{1}+r_{1} \\
q_{1}
\end{array}\right] \cdot\left[\begin{array}{c}
q_{2}+r_{2} \\
q_{2}
\end{array}\right]
$$

Finally, apply Lemma 1(ii), using $q_{3}$ and $r_{3}$, to the factor $1 /(s)$, yielding

$$
\frac{1}{(\boldsymbol{s})}=\sum_{s_{2}+r_{3}=s} \frac{x^{s_{2}\left(q_{3}+1\right)}}{\left(\boldsymbol{s}_{2}\right)}\left[\begin{array}{c}
q_{3}+r_{3} \\
q_{3}
\end{array}\right] \text {. }
$$

Inserting this expression into (10) gives the result:

$$
\begin{aligned}
\frac{1}{\left(\boldsymbol{d}_{1}\right)\left(\boldsymbol{d}_{2}\right)}= & \sum_{\substack{d_{1}=s_{1}+\boldsymbol{s}_{2}+r_{1}+r_{3} \\
d_{2}=t_{1}+2_{2}+r_{2}+r_{3}}} \frac{x^{s_{1} t_{1}+\left(d_{1}-r_{1}\right)\left(q_{1}+1\right)+\left(d_{2}-r_{2}\right)\left(q_{2}+1\right)+s_{2}\left(q_{3}+1\right)}}{\left(\boldsymbol{s}_{1}\right)\left(\boldsymbol{s}_{2}\right)\left(\boldsymbol{t}_{1}\right)} \\
& \cdot\left[\begin{array}{c}
q_{1}+r_{1} \\
q_{1}
\end{array}\right] \cdot\left[\begin{array}{c}
q_{2}+r_{2} \\
q_{2}
\end{array}\right] \cdot\left[\begin{array}{c}
q_{3}+r_{3} \\
q_{3}
\end{array}\right] \cdot
\end{aligned}
$$


For general $n$, the procedure is similar; Lemma 1 (ii) is used $n$ times, Lemma 2(ii), $(n-1)$ times and then Lemma 1(ii) once again. This completes the proof.

If $D=\left[d_{1}, \cdots, d_{n}\right]$, let $D^{*}$ denote $\left(0, d_{1}, d_{2}, \cdots, d_{n}\right)$. Then let $G(w, D)$ be the set of all ordered pairs of $n$-tableau $\left(T, T^{\prime}\right)$ with $\operatorname{sig} T=\operatorname{sig} T^{\prime}, \operatorname{con}\left(T^{\prime}\right)=D^{*}$, and $w$ as the weight of $T$.

THEOREM 2. (i) There is a 1-to-1 correspondence between the set $G(w, D)$ and the set $F(w, D)$ of all special $3 n$-section partitions of $w$ with signature $\left[r_{1}, \cdots, r_{n+1}, s_{1}, \cdots, s_{n}, t_{1}, \cdots, t_{n-1}\right]$ satisfying the system in (6).

(ii) Either side of equation (7) is the generating function $\sum_{w=0}^{\infty}|G(w, D)| x^{w}$, where $|G(w, D)|$ is the number of ordered pairs in $G(w, D)$.

Proof. C. Schensted's "insertion into tableau" procedure as developed by $\mathrm{D}$. Knuth ([3], Theorem 2, p. 715) gives a 1-to-1 correspondence between the set $E(w, D)$ of all $n$-section partitions of $w$ with signature $D$ and the set $G(w, D)$. Theorem 1(i) gives a 1-to-1 correspondence between the set $E(w, D)$ and the set $F(w, D)$.

6. Tableaux of type $\alpha$ and type $\beta$. Here specific types of tableaux, as characterized by Mead in [5], are defined. Our usage of $\alpha$ and $\beta$ is analogous to that in [2] and [4] and reverses that in [5].

For $w \geqq r(r-1) / 2$, let $M(r, w)$ denote the partition $\left(p_{1}, \cdots, p_{r}\right)$ of $w$ into $r$ distinct nonnegative integer parts $p_{i}$ that are as close to one another as possible, i.e., with $p_{i+1}-p_{i} \in\{1,2\}$ for $1 \leqq i \leqq r$ and with $p_{i+1}-p_{i}=2$ for at most one $i$.

Let $T$ be an $n$-tableau, $0 \leqq k \leqq n$, and let

$$
\left(a_{1}, \cdots, a_{n}\right), \quad\left(b_{1}, \cdots, b_{n}\right), \quad\left(c_{1}, \cdots, c_{k}\right)
$$

denote transposes of columns $A, B, C$ of $T$ (with lengths $n, n$, and $k$ ). $T$ is said to be of type $\beta$ if it satisfies one of the following four conditions:

(1) $T$ has a column $B$ whose transpose is an $M(n, w)$ for some $w$.

(2) For some $j$, the $(j-1)$-st and $j$ th columns are of the form $A$ and $B$ with $a_{i}=b_{i}$ for $i$ greater than some $t$ (which may be 0 ) and $\left(b_{1}, \cdots, b_{t}\right)=M(t, w)$ for some $w$.

(3) For some $j$, the $j$ th and $(j+1)$ st columns are of the form $B$ and $C$ such that $b_{i}=c_{i}$ for $i \leqq r$, where $r$ is an integer with $0 \leqq r \leqq k$ and $\left(b_{r+1}, \cdots, b_{n}\right)=M(n-r, w)$ for some $w$.

(4) $T$ has $A, B$, and $C$ as the $(j-1)$ st, $j$ th, and $(j+1)$-st 
columns such that $b_{i}=c_{i}$ for $i$ less than or equal to some $r \leqq k$, $\left(b_{r+1}, \cdots, b_{t}\right)=M(t-r, w)$ for some $t$ and $w$, and $a_{i}=b_{i}$ for $i>t$.

An $n$-tableau that is not of type $\beta$ is said to be of type $\alpha$. An ordered pair $\left(T, T^{\prime}\right)$ of $n$-tableaux with $\operatorname{sig} T=\operatorname{sig} T^{\prime}$ is said to be of type $\alpha$ or $\beta$ depending on whether the type of $T$ is $\alpha$ or $\beta$, respectively. Mead showed that the number of $\left(T, T^{\prime}\right)$ of type $\beta$ with $\operatorname{con}\left(T^{\prime}\right)=$ $D^{*}$ and $w$ as weight of $T$ is the dimension of a vector subspace of $R=F\left[y_{i j}\right]$ described in $\S 7$, where we give an explicit expression for this number. (This can be put in the form of an algorithm for obtaining this dimension.)

7. Partitions of types $\alpha$ and $\beta$. A special $3 n$-section partition $L$ of $w$, is said to be of type $\alpha$ if the degree $s_{n}$ of the $U_{n}$ of (5) is zero, i.e., $U_{n}$ is the ideal partition of $0 ; L$ is of type $\beta$ if $s_{n}>0$.

Let $\left(C_{\alpha}\right)$ denote the system of conditions (6) with the additional restriction that $s_{n}=0$ and let $\left(C_{\beta}\right)$ denote (6) with the added condition $s_{n}>0$. Let $F_{\alpha}(w, D)$ be the subset of $F(w, D)$ consisting of the $L$ with signature $D$ conditioned by $\left(C_{\alpha}\right)$ and let $F_{\beta}(w, D)$ consist of the remaining $L$ of $F(w, D)$. Also let $G_{\alpha}(w, D)$ and $G_{\beta}(w, D)$ denote the subsets of $G(w, D)$ of type $\alpha$ and type $\beta$, respectively.

Now let $N_{\alpha}(D, Q)$ and $N_{\beta}(D, Q)$ denote the expression on the right side of (7) when the sum is taken over $\left(C_{\alpha}\right)$ and $\left(C_{\beta}\right)$, respectively.

Let $V(w, D)$ be the subspace of $R=F\left[y_{i j}\right]$ generated by the $\pi$ of (3) with weight $w$ and signature $D$. Let $W_{n}$ be the Wronskian of $y_{1}, \cdots, y_{n}$ and $\left[W_{n}\right]$ be the principal differential ideal generated by $W_{n}$ in $R$. Among the ideals $I$ dealt with by the author in [2] are a family $\mathscr{F}$ such that $I \cap V(w, D)$ has the same dimension as $\left[W_{n}\right] \cap V(w, D)$. One such $I$ is the principal differential ideal generated by the $[n(n-1) / 2]$ th derivative of the product $y_{1} y_{2} \cdots y_{n}$; for this $I$ the $q_{i}$ introduced in $\S 5$ must be given by $0=q_{1}=q_{2}=\cdots=q_{n}$ and $q_{n+1}=n(n-1) / 2$. For all the ideals $\left(x_{0}, x_{1}, \cdots\right)$ of $\mathscr{F}$, the $q_{i}$ are chosen so that $q_{1}+q_{2}+\cdots+q_{n+1}=n(n-1) / 2$; this allows $x_{j}$ to be homogeneous and isobaric with the signature and weight of the $j$-th derivative of $W_{n}$. With such a choice of $Q$, the dimension of $\left[W_{n}\right] \cap V(w, D)$ is the same as the number $\left|F_{\beta}(w, D)\right|$ of special $3 n$ section partitions $L$ of $w$ with signature conditioned by $\left(C_{\beta}\right)$ and also equals the number $\left|G_{\beta}(w, D)\right|$ of ordered pairs $\left(T, T^{\prime}\right)$ of $n$-tableaux of type $\beta$ with $\operatorname{sig} T=\operatorname{sig} T^{\prime}$, con $T^{\prime}=D^{*}$, and $w$ as the weight of $T$.

Thus we have:

THEOREM 3. Let $q_{1}+q_{2}+\cdots+q_{n+1}=n(n-1) / 2$.

(i) There is a 1-to-1 correspondence between the sets $F_{\alpha}(w, D)$ 
and $G_{\alpha}(w, D)$ [and hence a 1-to-1 correspondence between $F_{\beta}(w, D)$ and $\left.G_{\beta}(w, D)\right]$.

(ii) $N_{\alpha}(D, Q)$ is the generating function for the number of elements in $F_{\alpha}(w, D)$ or in $G_{\alpha}(w, D)$ [and $N_{\beta}(D, Q)$ serves the same purpose for $F_{\beta}(w, D)$ or $\left.G_{\beta}(w, D)\right]$.

The fact that the $q_{i}$ of $Q$ in Theorem 3(ii) may be any nonnegative integers with $q_{1}+q_{2}+\cdots+q_{n+1}=n(n-1) / 2$ yields a number of identities on generating functions.

ExAmPle. Let $n=3$, and $D=[1,2,2]$. The system $\left(C_{\alpha}\right)$ in (6) becomes

$$
\left(C_{\alpha}\right):\left\{\begin{array}{l}
1=s_{1}+s_{2}+r_{1}+r_{4} \\
2=t_{1}+s_{2}+r_{2}+r_{4} \\
2=t_{2}+r_{3}+r_{4} .
\end{array}\right.
$$

Of the 20 possible $Q$ 's that satisfy $q_{1}+q_{2}+q_{3}+q_{4}=3$, we select $Q_{1}=(0,0,0,3)$ and $Q_{2}=(0,2,0,1)$. Since $N_{\alpha}\left(D, Q_{1}\right)=N_{\alpha}\left(D, Q_{2}\right)$ we have

$$
\begin{aligned}
& \sum_{C_{\alpha}} \frac{x^{5-\left(r_{1}+r_{2}+r_{3}\right)+s_{1} t_{1}+s_{2} t_{2}}}{\left(t_{1}\right)\left(t_{2}\right)\left(s_{1}\right)\left(s_{2}\right)}\left[\begin{array}{c}
3+r_{4} \\
3
\end{array}\right] \\
& \quad=\sum_{C_{\alpha}} \frac{x^{9-\left(r_{1}+3 r_{2}+r_{3}\right)+s_{1} t_{1}+s_{2} t_{2}}}{\left(t_{1}\right)\left(t_{2}\right)\left(s_{1}\right)\left(s_{2}\right)}\left[\begin{array}{c}
2+r_{2} \\
2
\end{array}\right]\left[\begin{array}{c}
1+r_{1} \\
1
\end{array}\right]
\end{aligned}
$$

where the sum is taken over the 28 solutions to the system $C_{\alpha}$.

Each side of this identity is also the generating function

$$
\sum_{w=0}^{\infty}\left|G_{\alpha}(w, D)\right| x^{w}
$$

for the ordered pairs $\left(T, T^{\prime}\right)$ of $n$-tableaux of type $\alpha$ with $\operatorname{con}\left(T^{\prime}\right)=$ $D^{*}=(0,1,2,2)$ [and $w$ as the weight of $T$ ].

\section{REFERENCES}

1. P. Doubilet, Gian-Carlo Rota and J. Stein, On the foundations of combinatorial theory: IX Combinatorial methods in invariant theory, Studies in Applied Mathematics, Vol. LIII, No. 3 Sept. (1974), 185-216.

2. R. M. Grassl, Levi structures for polynomial ideals, thesis, University of New Mexico, (August, 1974).

3. D. E. Knuth, Permutations, matrices, and generalized Young tableaux, Pacific J. Math., 34 (1970), 709-726.

4. H. Levi, On the structure of differential polynomials and on their theory of ideals, Trans. Amer. Math. Soc., 51 (1942), 532-568. 
[5] D. G. Mead, Determinantal ideals, identities, and the Wronskian, Pacific J. Math., 42 (1972), 165-175.

Received April 30, 1976.

The University of New Mexico

Albuquerque, NM 87131 


\section{PACIFIC JOURNAL OF MATHEMATICS}

\section{EDITORS}

RICHARD ARENS (Managing Editor)

University of California

Los Angeles, CA 90024

R. A. BEAUMONT

University of Washington

Seattle, WA 98105

C. C. Moore

University of California

Berkeley, CA 94720

\section{J. DugundJI}

Department of Mathematics

University of Southern California

Los Angeles, CA 90007

R. Finn and J. Milgram

Stanford University

Stanford, CA 94305

\section{ASSOCIATE EDITORS}

\section{E. F. BECKENBACH}

B. H. NEUMANN

F. WoLF

K. YOSHIDA

\section{SUPPORTING INSTITUTIONS}

\author{
UNIVERSITY OF BRITISH COLUMBIA \\ CALIFORNIA INSTITUTE OF TECHNOLOGY \\ UNIVERSITY OF CALIFORNIA \\ MONTANA STATE UNIVERSITY \\ UNIVERSITY OF NEVADA \\ NEW MEXICO STATE UNIVERSITY \\ OREGON STATE UNIVERSITY \\ UNIVERSITY OF OREGON \\ OSAKA UNIVERSITY
}

\author{
UNIVERSITY OF SOUTHERN CALIFORNIA \\ STANFORD UNIVERSITY \\ UNIVERSITY OF HAWAII \\ UNIVERSITY OF TOKYO \\ UNIVERSITY OF UTAH \\ WASHINGTON STATE UNIVERSITY \\ UNIVERSITY OF WASHINGTON \\ AMERICAN MATHEMATICAL SOCIETY
}

The Supporting Institutions listed above contribute to the cost of publication of this Journal, but they are not owners or publishers and have no responsibility for its content or policies.

Mathematical papers intended for publication in the Pacific Jaurnal of Mathematics should be in typed form or offset-reproduced, (not dittoed), double spaced with large margins. Please do not use built up fractions in the text of your manuscript. You may however, use them in the displayed equations. Underline Greek letters in red, German in green, and script in blue. The first paragraph or two must be capable of being used separately as a synopsis of the entire paper. Items of the bibliography should not be cited there unless absolutely necessary, in which case they must be identified by author and Journal, rather than by item number. Manuscripts, in triplicate, may be sent to any one of the editors. Please classify according to the scheme of Math. Reviews, Index to Vol. 39. All other communications should be addressed to the managing editor, or Elaine Barth, University of California, Los Angeles, California, 90024.

The Pacific Journal of Mathematics expects the author's institution to pay page charges, and reserves the right to delay publication for nonpayment of charges in case of financial emergency

100 reprints are provided free for each article, only if page charges have been substantially paid. Additional copies may be obtained at cost in multiples of 50 .

The Pacific Journal of Mathematics is issued monthly as of January 1966. Regular subscription rate: $\$ 7200$ a year (6 Vols., 12 issues). Special rate: $\$ 36.00$ a year to individual members of supporting institutions.

Subscriptions, orders for back numbers, and changes of address should be sent to Pacific Journal of Mathematics, 103 Highland Boulevard, Berkeley, California, 94708.

PUBLISHED BY PACIFIC JOURNAL OF MATHEMATICS, A NON-PROFIT CORPORATION

Printed at Kokusai Bunken Insatsusha (International Academic Printing Co., Ltd.). 8-8, 3-chome, Takadanobaba, Shinjuku-ku, Tokyo 160, Japan.

Copyrit (C) 1975 by Pacific Journal of Mathematics Manufactured and first issued in Japan 


\section{Pacific Journal of Mathematics \\ Vol. 69, No. $2 \quad$ June, 1977}

Carol Alf and Thomas Alfonso O'Connor, Unimodality of the Lévy spectral

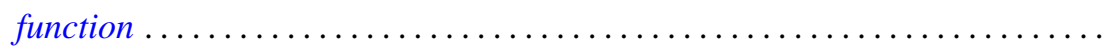

S. J. Bernau and Howard E. Lacey, Bicontractive projections and reordering of

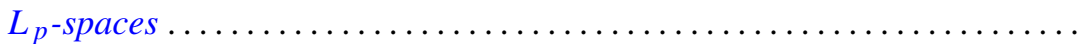

Andrew J. Berner, Products of compact spaces with bi-k and related spaces..... 303

Stephen Richard Bernfeld, The extendability and uniqueness of solutions of ordinary differential equations ...............................

Marilyn Breen, Decompositions for nonclosed planar m-convex sets ..........

Robert F. Brown, Cohomology of homomorphisms of Lie algebras and Lie

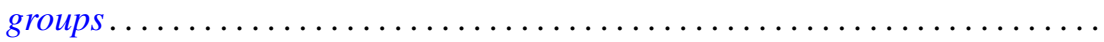

Jack Douglas Bryant and Thomas Francis McCabe, A note on Edelstein's iterative test and spaces of continuous functions ....................

Victor P. Camillo, Modules whose quotients have finite Goldie dimension ....... 333

David Downing and William A. Kirk, A generalization of Caristi's theorem with

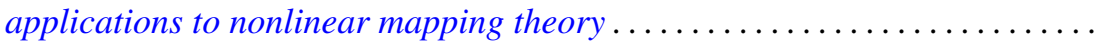

Daniel Reuven Farkas and Robert L. Snider, Noetherian fixed rings ...........

Alessandro Figà-Talamanca, Positive definite functions which vanish at

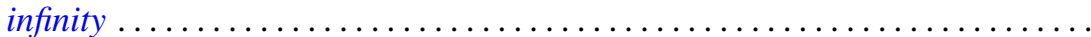

Josip Globevnik, The range of analytic extensions .................. 365

André Goldman, Mesures cylindriques, mesures vectorielles et questions de

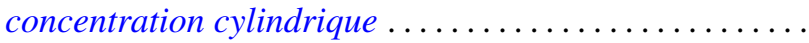

Richard Grassl, Multisectioned partitions of integers..........

Haruo Kitahara and Shinsuke Yorozu, A formula for the normal part of the

Laplace-Beltrami operator on the foliated manifold .... .

Marvin J. Kohn, Summability $R_{r}$ for double series .........

Charles Philip Lanski, Lie ideals and derivations in rings with involution ..

Solomon Leader, A topological characterization of Banach contractions . .

Daniel Francis Xavier O’Reilly, Cobordism classes of fiber bundles . .

James William Pendergrass, The Schur subgroup of the Brauer group . .

Howard Lewis Penn, Inner-outer factorization of functions whose Fourier series

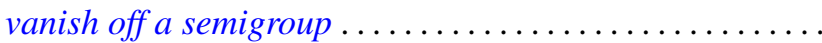

501

William T. Reid, Some results on the Floquet theory for disconjugate definite

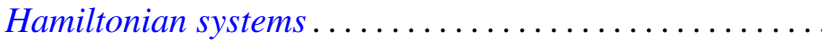

Caroll Vernon Riecke, Complementation in the lattice of convergence

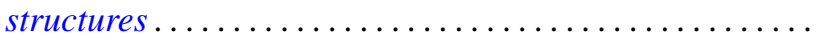

Louis Halle Rowen, Classes of rings torsion-free over their centers ......... 527

Manda Butchi Suryanarayana, A Sobolev space and a Darboux problem ....... 535

Charles Thomas Tucker, II, Riesz homomorphisms and positive linear maps.... 551

William W. Williams, Semigroups with identity on Peano continua ........... 557

Yukinobu Yajima, On spaces which have a closure-preserving cover by finite 